\title{
Designing Science Learning Domains for 2e (Twice Exceptional) Students
}

\author{
Ümmüye Nur Tüzün ${ }^{*}$ \\ ${ }^{1}$ Ostim Technical University and Ministry of Turkish National Education, Turkey \\ *Corresponding Author u tuzun@hotmail.com
}

\begin{abstract}
2e (twice-exceptional) students are gifted and differently-abled, so they need specific learning domains according to their needs. This research aimed to design science learning domains for a $2 \mathrm{e}$ (gifted and blind) student to enhance his critical thinking in his special learning needs in Ankara province in Turkey in the 2020-2021 academic year's first term. Single-subject research was employed. The $2 \mathrm{e}$ student was ten years old. Through the application process, the $2 \mathrm{e}$ student argued $3 \mathrm{D}$ modeled Schrödinger's cat thought experiment. The main application's intervention was conducted to provide the research's internal validity since it was single-subject research. Through the intervention application, the 2e student argued $3 \mathrm{D}$ modeled Schrödinger's twin cats thought experiment. We noted both social dialectic argumentation processes as texts, and these texts were used as data collecting tools. Descriptive analysis was utilized to gathered data. The study showed that the 2e student could construct arguments containing claim, data, warrant, and weak rebuttals in the main application, which meant his argumentation quality level was average, so his critical thinking too. In contrast, the $2 \mathrm{e}$ student-constructed arguments containing claim, data, weak rebuttal, and rebuttal meant his argumentation quality level enhanced his critical thinking.
\end{abstract}

Keywords 2e Students, Science Learning, Chemistry Thought Experiments, 3D Modelled Paintings, Argumentation, Critical Thinking

\section{INTRODUCTION}

For many years, parents and teachers have been perplexed about students who have dramatic learning strengths in some areas and equally dramatic learning weaknesses in other areas. In addition, these students appear to defy accurate labeling: Are they gifted or learning differently-abled? Finally, the debate has come to an end. Educators now recognize these students as "twiceexceptional (2e)." (Winebrenner, 2003). Technically, 2e refers to students who are identified as gifted and talented and also diagnosed with one or more of the special education categories defined by the Individuals with Disabilities Education Act (IDEA), except for those students with cognitive disabilities (Reis, Baum \& Burke, 2014).

According to "national association for gifted children and the $2 \mathrm{e}$ center for research and professional development at Bridges Academy in Los Angeles", "Twiceexceptional learners are students who demonstrate the potential for high achievement or creative productivity in one or more domains. The domains include math, science, technology, the social arts, the visual, spatial, or performing arts or other human productivity areas and manifest one or more disabilities as defined by federal or state eligibility criteria. These disabilities include specific learning disabilities, speech and language disorders; emotional/behavioral disorders; physical disabilities; autism spectrum disorders (ASD); or other health impairments, such as attention deficit/hyperactivity disorder (ADHD). Unfortunately, these disabilities and high abilities combine to produce a unique population of students who may fail to demonstrate high academic performance or specific disabilities. As a result, their gifts may mask their disabilities, and their disabilities may mask their gifts." (Reis, Baum \& Burke, 2014 p. 222).

Twice-exceptional students have great potential to succeed. However, many become incredibly frustrated and have difficulty coping with the discrepancy between their giftedness and learning disability. Their struggle to cope with frustration often leaves them feeling inadequate, disappointed, and angry. All of these negatively affect their self-concept (Williams-King, 2005), so in literature, there are some tips for teachers for teaching these twiceexceptional students properly since their regular classes could not be able to provide all their specific learning

Received: 22 January 2021

Revised: 6 March 2021

Published: 1 July 2021 
needs. For specific disabilities, teachers must teach students to appreciate individual differences. They must be aware of these students' visual and tactile-kinaesthetic needs for learning success. The teachers (a) teach basic concepts first and then the details, (b) teach students to take realistic short-term goals and to take credit for reaching these goals, (c) integrate the previously learned knowledge with the new one including all the senses in learning activities, (d) provide specific instruction in organizational techniques, (e) use any available technology for improving students' productivity, (f) allow students to take tests in separate, $(\mathrm{g})$ supervised environments so they can either read the text aloud to themselves or have someone else read it to them (Winebrenner, 2003). For high academic performance, students must be confronted with different topics which they do not find a chance to experience at their regular schools (Rogers, 2007). The teaching environments must be designed to make students interrogate new information, overthink, and organize and link (Stott \& Hobden, 2016). In much more precisely, teachers must (a) give daily challenge to the students in their specific areas of talent, (b) provide opportunities to their students to work independently in their areas of passion, (c) provide various forms of subject-based and grade-based acceleration to the students as their educational needs require, (d) also provide opportunities for them to socialize, and (e) also differentiate the instructional delivery (Rogers, 2007). According to Sak (2017), there are different options for making the learning domains enriched for gifted students. Giving way to gifted students for new and exciting topics in out of school times, for example at summer camps, making gifted students study individually on their specific passion areas, for example, project studies, independent enrichment studies, for example designing innovative learning domains, and field studies are among these options.

Like educators, parents want the education policies for 2e students to make their children's giftedness maximized and their disabilities minimized (Besnoy et al., 2015), so it would be beneficial to highlight designing proper learning environments for $2 \mathrm{e}$ students according to their needs one more time. With appropriate learning environments, the $2 \mathrm{e}$ students also would not fall behind their peers. Because falling behind their peers and low success would trigger their lack of motivation and lower self-concept, which were undesirable positions (Barber \& Mueller, 2011; Beckley, 1998).

Yılmaz-Yenioğlu and Melekoğlu (2020) stated in their research that 'organizing learning domains for twiceexceptional students' researches are so less in literature and much needed so in this research it was aimed to design science learning domains for a $2 \mathrm{e}$ (gifted and blind) student for enhancing his critical thinking in means of his unique learning needs. This study would contribute to the gap in the literature in means of modeling how to organize learning domains for twice-exceptional students according to their needs since it is suggested in the literature to design learning domains for twice-exceptional students according to their needs so that they would not bewilder inconsistencies in their academic lives (Assouline, FoleyNicpon, \& Huber, 2006; Baldwin, Omdal \& Pereles, 2015).

\section{METHOD}

This research was conducted with a $2 \mathrm{e}$ student (gifted and blind) at a school for gifted in Ankara province, in Turkey, in the 2020-2021 academic year. Single-subject research was used in the research. Single-subject research plays an essential role in developing evidence-based practice in special education (Horner et al., 2005). Singlesubject research is experimental rather than correlational or descriptive, and its purpose is to document causal or functional relationships between independent and dependent variables. In addition, single-subject research employs within- and between-subjects comparisons to control significant threats to internal validity and requires systematic replication to enhance external validity (Martella, Nelson \& Marchand-Martella, cf., Horner et al., 2005).

The 2e student is gifted and blind. The sex of the subject is male. It would be helpful to highlight that under optimized conditions such as enough light and specially designed glasses, the $2 \mathrm{e}$ student could see a bit. He is ten years old and is educating at a secondary school for blind students. He is also educating at a school for the gifted as being his second legal school. Because of his blindness, according to his specific learning needs, the thought experiments used in the research were modeled as $3 \mathrm{D}$ (three-dimensional) paintings by the researcher as teaching materials. The 3D paintings told the thought experiments scenario to the 2e student by making him touch every canvas. Because of his gift and according to gifted education enrichment standards for enhancing students' metacognitive skills to a much more upper level, the social dialectic argumentation processes for both thought experiments for enhancing the 2e student's critical thinking were employed. The $2 \mathrm{e}$ student did not do a rhetoric argumentation process. In other words, he did not just justify his thoughts; instead of in a social dialectic argumentation process, he influenced his researcher teacher too for arguing his thoughts. His attendance at the research is based on his willingness. His parent's approval form and the school's approval form for gifted students are presently based on research ethics. He was also informed that he could put off the research based on research ethics too.

The application process was through 90 minutes. During the application process, Schrödinger's cat thought experiment from literature was discussed in a social dialectic argumentation learning domain with the 2e student for enhancing his critical thinking. For critical 
thinking measurement criteria, the 2e student's arguments in a socio dialectic argumentation process were evaluated. Since the Cambridge international thinking skills syllabus (2020-2022) offered argument construction skills as criteria for evaluating critical thinking improvement, the same way was employed in this research. The primary research intervention was conducted with an original Schrödinger's twin cats thought experiment with the same 2e student to enhance his critical thinking through a social argumentation learning domain for the internal validity of the research. The thought experiments must be uppercognitive since the student is gifted; also, the thought experiments were modeled on two different canvas with 3D (three-dimensional) paints before the application process by the researcher teacher since the student is blind. The data collection tools were written texts of oral social dialectic argumentation processes, one for the main science learning domain, another for the intervention of the primary science learning domain. Data were analyzed by descriptive analysis. For descriptive analysis, codes and categories were taken from literature.

During the 3D modeled thought experiments based on the social dialectic argumentation process, Cunningham's model was utilized for designing the learning domains for the 2e student (cf., Tozlu, Gülseven \& Tüysüz, 2019). According to this model, there are five steps for designing the learning domains:

- Ask: What are the problems? What are the limitations?

- Imagine: Do brainstorming. Choose the much more plausible conclusion among the alternatives.

- Plan: Draw a diagram. Determine the materials you need.

- Design: Construct your model. Test it.

- Improve: Argue how to make the model much better. Check all the steps from the beginning.

For the main single-subject research's application process:

\section{- Ask}

A thought experiment is asked what would happen if a given scenario becomes true (Gendler, 1998). In a thought experiment, one could solve the given problem in a given scenario by integrating the previously learned knowledge into the thought experiment to gain new knowledge (Cooper, 2005). A thought experiment contains a hypothetical world, a hypothesis, an experimental process carried out in the mind's laboratory, results derived from previous experiences, and a conclusion made from these results (Reiner, 1998). A thought experiment states a hypothesis's conclusions. Nevertheless, the hypothesis is true or not (Rescher, 1991). A thought experiment could be reconstructed in the means of an argument since a good thought experiment means a good argument, a bad thought experiment means a bad one (Ireson, 2005; Norton, 1991), so thought experiments are crucial for an argumentation process (Lattery, 2001). According to Toulmin (2003), an argument means a claim (the primary hypothesis), data (the conditions on which the primary hypothesis is constructed), warrant (the situation engaging the data and the claim), backing (the guarantee of the warrant), rebuttal (the circumstances which made a claim and the warrant invalid), and limitation (the conditions explaining the borders of the argument).

In contrast, an argumentation process means coordinating these compounds (Osborne, Erduran \& Simon, 2004). A rhetoric argumentation process means one trying to assure the others of his/her argument, whereas a social dialectic argumentation process means individuals are constructing their arguments together by arguing (Driver, Newton, \& Osborne, 2000). The concepts are given above, the explanations of what thought experiment, argument, and argumentation are, were introduced to the 2e student by telling. And the form literature Schrödinger's cat thought experiment was given to the $2 \mathrm{e}$ student as a problem statement. The thought experiment was read to the 2e student as follows:

"Suppose a cat is enclosed in a sealed steel chamber to be completely isolated from the outside world. Along with the cat in the chamber is a device capable of releasing a sufficient quantity of deadly poison into the chamber's atmosphere to kill the cat instantly. A quantum-mechanical measurement process triggers the operation of the device."

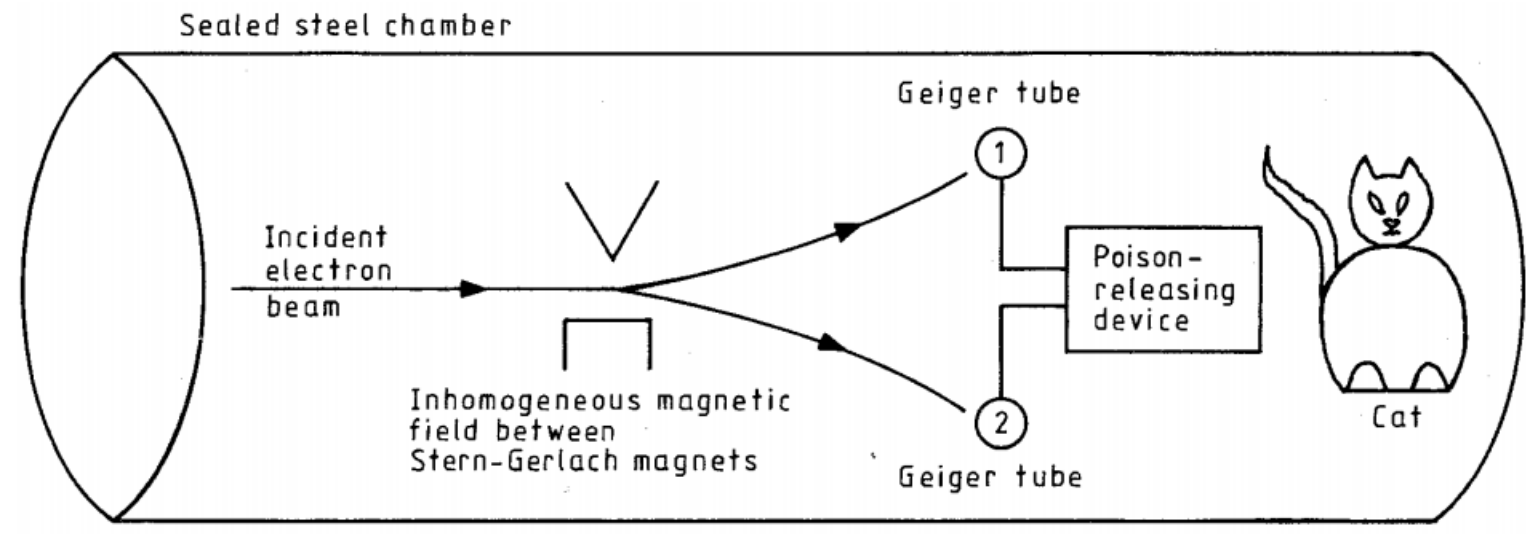

Figure 1 Schematic representation of Schrödinger's cat thought experiment (Villiars, 1986) 


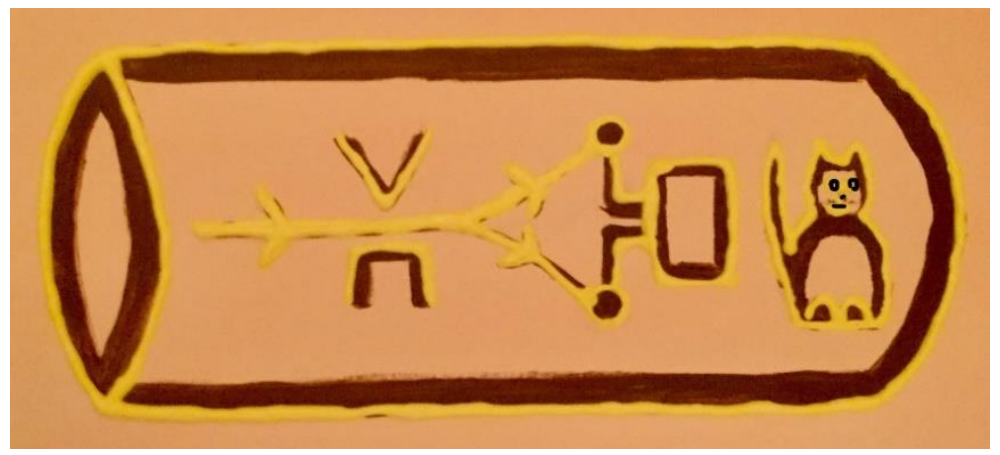

Figure 2 Schematic representation of Schrödinger's cat thought experiment on canvas by 3D painting (illustrated by researcher teacher)

(Villiars, 1986). The scheme for Schrödinger's cat thought experiment in its original form is shown in Figure 1.

If it is supposed at the beginning of the thought experiment that electron radiation intensity was so small, then there would be a paradox for the cat to be alive or dead at the end of the experiment based on a series of quantum calculations (Villiars, 1986).

So by this way, the 2e student exposed to the thought experiment's question as "What would happen if so small a quantity of radiation occurred? Would the cat be alive or dead?" (The 2e student was informed that this is only a thought experiment, it is not a real one, doing experiments with animals is against ethics except pharmaceutical ones.)

\section{- Imagine:}

The $2 \mathrm{e}$ student made a brainstorming with his researcher teacher. Finally, he argued all the alternatives in a social dialectic argumentation learning domain with his researcher teacher before concluding.

\section{- Plan:}

The researcher teacher had modeled the thought experiment's process on canvas using 3D paints before the application process. It is not practical drawing the painting with the 2e student during the application since the 3D paints need time to dry. Furthermore, the whole 3D painting must also be dried before the application process since the $2 \mathrm{e}$ student would touch the whole painting's figures one by one to make meaningful the images in his mental scheme. In other words, because of the student's visual disability, he needs some specifically constructed learning domains that would allow him to see the whole scene with his hands.

In this given knowledge, the 2e students touched the whole painting representing Schrödinger's cat thought experiment scheme. He asked all the figures one by one to the researcher teacher. Together they tried to make the thought experiment's scheme meaningful for the $2 \mathrm{e}$ student. The teacher had noted the Schrödinger's cat thought experiment in Braille alphabet in Turkish too before the application, but the $2 \mathrm{e}$ student did not need it since the teacher told the thought experiment, he touched the 3D painting instead and asked whatever he wanted for making the thought experiment meaningful.

\section{- Design:}

The 2e student-tested Schrödinger's cat thought experiment's 3D painting by his hands to test the painting in means of plausibility. The 3D painting of Schrödinger's cat thought experiment scheme could be seen in Figure 2.

\section{- Improve:}

In the end, the 2e student decided on Schrödinger's cat thought experiment by arguing the thought experiment with his researcher teacher in a social dialectic argumentation process. The researcher teacher noted this last social dialectic argumentation process as a text to use as a data collection device later.

For the primary single-subject research's intervention process:

\section{- Ask}

For the intervention of the whole process, Schrödinger's twin cats thought experiment was derived from the Schrödinger's cat thought experiment by the researcher teacher before the intervention process. Schrödinger's twin cat thought experiment was read to the 2e student as follows:

"Suppose two twin cats are enclosed in a sealed steel chamber to be completely isolated from the outside world. Along with the cat in the chamber is a device capable of releasing a sufficient quantity of deadly poison into the chamber's atmosphere to kill both of the cats instantly. A quantum-mechanical measurement process triggers the operation of the device." (derived from Villiars, 1986).

Suppose that electron radiation intensity was not so small at the beginning of the thought experiment, then one of the twin cats was poisoned. The 2e student exposed to the thought experiment's question as "Would the twin cat be poisoned too or not? And why?" (The 2e student was made to remember that it is not an actual experiment since doing experiments with animals is against ethics.)

\section{- Imagine:}

The 2e student made a brainstorming with his researcher teacher again. Finally, he just argued all the alternatives in a social dialectic argumentation learning 


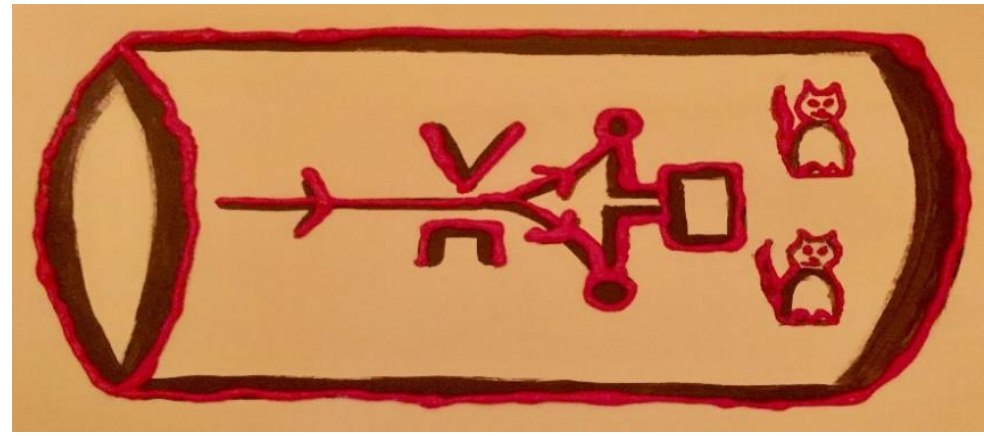

Figure 3 Schematic representation of Schrödinger's twin cats thought experiment on canvas by 3D painting (illustrated by researcher teacher)

domain with his researcher teacher before concluding again.

\section{RESULT AND DISCUSSION}

\section{- Plan:}

The researcher teacher modeled the new thought experiment's process on canvas using $3 \mathrm{D}$ paints before the application process. It is not practical drawing the painting with the $2 \mathrm{e}$ student during the application since the $3 \mathrm{D}$ paints need time to dry. The whole 3D painting must also be dried before the application process since the 2e student would touch the whole painting's figures one by one to make meaningful the images in his mental scheme, just like the previous application process. In other words, because of the student's visual disability, he needs some specifically constructed learning domains that would allow him to see the whole new scene with his hands.

In this given knowledge, the 2e students touched the whole painting representing Schrödinger's twin cats thought experiment scheme. He asked all the figures one by one to the researcher teacher again. Together they tried to make the thought experiment's scheme meaningful for the $2 \mathrm{e}$ student again. The teacher had noted the Schrödinger's twin cats thought experiment in Braille alphabet in Turkish too before the application, but the $2 \mathrm{e}$ student did not need it since the teacher told the thought experiment, he touched the 3D painting instead and asked whatever he wanted for making the thought experiment meaningful.

\section{- Design:}

The 2e student is tested Schrödinger's twin cats through the experiment's 3D painting by his hands to test the painting in means of plausibility. The 3D painting of Schrödinger's twin cats thought experiment scheme could be seen in Figure 3.

\section{- Improve:}

The 2e student decided Schrödinger's twin cats thought experiment by arguing the thought experiment with his researcher teacher in a social dialectic argumentation process just like the previous social dialectic argumentation process. The researcher teacher noted this last social dialectic argumentation process as a text again to use as a data collection device later.

\subsection{The 2e student's arguments about Schrödinger's cat thought experiment}

The 2e student argued Schrödinger's cat thought experiment with his researcher teacher in a social dialectic argumentation process. The researcher teacher noted this social dialectic argumentation process as a text to use as a data collection device later. For analyzing the social argumentation process, descriptive analysis was utilized. For codes, Toulmin's (2003) argument pattern components were used. These components are data, claim, warrant, backing and rebuttal. The limitation component of the Toulmin argument pattern was not taken as code.

For analyzing the social argumentation process, argumentation quality levels from the literature were utilized. For example, Erduran, Simon \& Osborne (2004) defined the argumentation quality levels like level 1 (arguments containing the only claim), level 2 (arguments containing claim and data/warrant/rebuttal), level 3 (arguments containing weak rebuttal addition to level 2 components), level 4 (arguments containing rebuttal addition to level 2 components), and level 5 (arguments containing two or more rebuttals addition to level 2 components).

The Schrödinger's cat thought experiment social argumentation process and its analysis:

2e student: Radiation would occur as electron radiation (claim) (level 1).

Subatomic particles' velocities are so high. For example, since an electron is a subatomic particle, its velocity would be high (claim, data, and warrant) (level 2).

The quantum-mechanical measurement process would trigger the poison releasing device regardless of the electron radiation quantity. (The 2e student refers that small radiation quantities could produce considerable energy.) (claim, data) (level 2).

But teacher, is the poison releasing device sealed? (weak rebuttal) (level 3).

Teacher, is the poison releasing device thick? (The 2e student queries to understand how the first mechanism affects the second mechanism.) (weak rebuttal) (level 3). 
Researcher teacher: Yes. For both of your questions.

The first mechanism would trigger the second (claim) (level 1).

The second mechanism would give harm to the cat (claim) (level 1).

It would also give harm to the chamber (regardless of its material as steel because we are talking about nuclear reactions.) (claim) (level 1). 1).

So the people would right recognize the process too (claim) (level

The Schrödinger's cat thought experiment social argumentation process analysis was shown in Table 1. The 2e student constructed nine arguments during the social dialectic argumentation process. The researcher teacher did not construct arguments herself. She only guided the social dialectic argumentation process; in other words, she was there whenever the 2e students needed her mentally for arguing. From the 2e student's arguments analysis, it could be seen that the 2e student managed to construct claims, data, warrant, and weak rebuttals. As Erduran, Simon \& Osborne (2004) offered in literature, arguments having rebuttals mean much more qualified levels in arguing, so it could be said that the 2e student's Schrödinger's cat thought experiment social argumentation process was an average one. The $2 \mathrm{e}$ student experience making a qualified argumentation process also contributed positively to his critical thinking.

\subsection{The $2 \mathrm{e}$ student's arguments about Schrödinger's twin cats thought experiment}

For the primary research intervention, the $2 \mathrm{e}$ student argued Schrödinger's twin cats thought experiment with his researcher teacher in a social dialectic argumentation process. The researcher teacher noted this social dialectic argumentation process as a text to use as a data collection device later. For analyzing the social argumentation process, descriptive analysis was utilized. Toulmin's (2003) argument pattern components (claim, data, warrant, backing, and rebuttal) are for codes. For categories, Erduran, Simon \& Osborne (2004) argumentation quality levels (levels according to their rebuttal degrees).

The Schrödinger's twin cats thought experiment social argumentation process and its analysis:

Table 1 The Schrödinger's cat thought experiment social argumentation process analysis

\begin{tabular}{llll}
\hline $\begin{array}{l}\text { Argumentation } \\
\text { quality levels }\end{array}$ & Level 1 & Level 2 & Level 3 \\
\hline Frequency (f) & $\mathrm{f}: 5$ & $\mathrm{f}: 2$ & $\mathrm{f}: 2$ \\
\hline
\end{tabular}

Table 2 The Schrödinger's twin cats thought experiment social argumentation process analysis

\begin{tabular}{lllll}
\hline $\begin{array}{l}\text { Argumentation } \\
\text { quality levels }\end{array}$ & $\begin{array}{l}\text { Level } \\
\mathbf{1}\end{array}$ & $\begin{array}{l}\text { Level } \\
\mathbf{2}\end{array}$ & $\begin{array}{l}\text { Level } \\
\mathbf{3}\end{array}$ & $\begin{array}{l}\text { Level } \\
4\end{array}$ \\
\hline Frequency (f) & $\mathrm{f}: 1$ & $\mathrm{f}: 3$ & $\mathrm{f}: 1$ & $\mathrm{f}: 1$ \\
\hline
\end{tabular}

DOI: $10.17509 / j s l .04 i 3.31570$
2 e student: Teacher, what happened to this cat? (He did not like the cat shape, in other words, the cat's shape could be a little different from his previously experienced ones because of the researcher teacher's less capability at arts.)

Researcher teacher: Because my capability at arts is limited. (She laughs.)

2 e student: I understood. (He smiles too.)

$2 e$ student: Why are cats? (weak rebuttal against experimenting with animals, nevertheless it is only a thought experiment) (level 3).

Researcher teacher: No, no, experimenting with cats is not ethical. We are doing this experiment only in the laboratory of mind (The researcher's teacher reminded the $2 e$ student that it is only a thought experiment again.)

2e student: The whole process would be just like the previous one (claim) (level 1).

The other twin cat would be poisoned, too, because they are in the same chamber (claim, warrant) (level 2).

Since the cats are twins, their organisms' functions are alike (claim, data) (level 2).

Researcher teacher: What is your conclusion?

2e student: Because of the whole, both would be poisoned (claim, data) (level 2).

If the cats had different immune systems, then the poison's effect on each of the cats would be different, too (rebuttal) (level 4).

The Schrödinger's twin cats thought experiment social argumentation process analysis was shown in Table 2 . The 2e student-constructed six arguments during the social dialectic argumentation process. The researcher's teacher guided the social dialectic argumentation process. From the 2 e student's arguments analysis, it could be seen that the 2e student managed to construct claims, data, weak rebuttal, and rebuttal. Erduran, Simon \& Osborne (2004) offered in the literature that arguments having rebuttals mean much more qualified levels in arguing. It could be said that the 2e student's Schrödinger's twin cats thought experiment social argumentation process was a bit much more than the average one as the process included level 4 argument but only one. It could also be said that the intervention of the study is meaningful for the internal validity and also successful in means of argumentation quality levels. By making the 2e student experience a much more qualified argumentation process, this intervention process also contributed positively to his critical thinking too.

\section{CONCLUSION}

This research designed science learning domains for a 2e (gifted and blind) student to enhance his critical thinking in his special learning needs. Two parallel thought experiments, each modeled with 3D paintings, were presented to the 2e student. Because the research was single-subject research, the intervention process was needed for the research's internal validity. In the first thought experiment (Schrödinger's cat - from literature), the $2 \mathrm{e}$ student could manage to construct nine arguments during a social dialectic argumentation process, including level 1, level 2, and level 3 argumentation quality levels. In 
the intervention thought experiment (Schrödinger's twin cats - an original one), the 2e student could manage to construct six arguments during a social dialectic argumentation process which included level 1, level 2, level 3 , and level 4 argumentation quality levels which would ensure the internal validity of the research and also would mean enhancing the 2e student's critical thinking.

It could be seen from the literature that "designing science learning domains for 2e students" is a new topic and is not so common (Yılmaz-Yenioğlu \& Melekoğlu, 2020). By telling this research's application processes in detail, it was also aimed to contribute to the literature for educators working or researchers who would work in this field, so it would also be beneficial to give some little tips for teachers based on experiences gained through this research.

2e students do not mean they do not have uppercognitive thinking skills. Because they are gifted, they need the acceleration and enrichment studies too much; nevertheless, their specific needs such as physical disabilities (cerebral palsy, visual disability) or learning difficulties in specific areas. In this research, acceleration and enrichment were provided to 2e students for designing learning domains based on 3D materials according to their physical needs. However, the 2e student had no difficulty using upper-cognitive thinking, arguing, making plausible decisions, justifying his claims, or rebutting his claims.

For designing learning domains, doing preparations before the applications according to 2e students' specific needs is essential. For this aim, he was having an opinion about 2e students' specific needs before the lessons would be crucial. For example, in this research, both 3D modeling of the thought experiments as 3D paintings and thought experiments written in Braille alphabet were provided to $2 \mathrm{e}$ student, but he only used the 3D paintings since the researcher teacher read him the experiments. But more than one 2e student this would not be so practical. In these circumstances, maybe Braille written thought experiments would be needed by the 2e students since the teacher's interest and shared among the students.

\section{REFERENCES}

Assouline, S. G., Foley-Nicpon, M., \& Huber, D. H. (2006). The impact of vulnerabilities and strengths on the academic experiences of twice-exceptional students: A message to school counsellors. Professional School Counselling, 10(1), 14-24.

Baldwin, L., Omdal, S. N., \& Pereles, D. (2015). Beyond stereotypes: Understanding, recognizing and working with twice-exceptional learners. Teaching Exceptional Children, 47(4), 216-225.

Barber, C., \& Mueller, C. T. (2011). Social and self-perceptions of adolescents identified as gifted, learning disabled and twiceexceptional. Roeper Review, 33, 109-120.

Beckley, D. (1998). Gifted and learning disabled: Twice-exceptional students. National Research Center on Gifted and Talented, 2-7.

Besnoy, K. D., Swoszowski, N. C., Newman, J. L., Floyd, A., Jones, P., \& Byrne, C. (2015). The advocacy experiences of parents of elementary age, twice-exceptional children. Gifted Child Quarterly, 59(2), 108-123.
Cambridge International AS \& A Level Thinking Skills 9694, Syllabus (2020-2022),

https://www.cambridgeinternational.org/Images/415052-20202022-syllabus.pdf.

Cooper, R. (2005). Thought experiments. Metaphilosophy, 36(3), 328-347.

Driver, R., Newton, P., \& Osborne, J. (2000). Establishing the norms of scientific argumentation in classrooms. Science Education, 84, $287-$ 312.

Erduran, S., Simon, S., \& Osborne, J. (2004). TAPping into argumentation: Developments in the application of Toulmin's argument pattern for studying science discourse. Science Education, 88, 915-933.

Gendler, T. (1998). Galileo and the indispensability of scientific thought experiment. British Journal for the Philosophy of Science, 49, 397-424.

Horner, R. H., Carr, E. G., Halle, J., Mcgee, G., Odom, S., \& Wolery, M. (2005). The use of single-subject research to identify evidencebased practice in special education. Exceptional Children, 71(2), 165179.

Ireson, G. (2005). Einstein and the nature of thought experiments. School Science Review, 86(317), 47-51.

Lattery, M. J. (2001). Thought experiments in physics education: A simple and practical example. Science and Education, 9, 1-13.

Norton, J. (1991). Thought experiments in Einstein's work. T. Horowitz \& G. J. Massey (Eds.), Thought Experiments in Science and Philosophy, (pp. 129-144). Rowman \& Littlefield Publishers.

Osborne, J., Erduran, S., \& Simon, S. (2004). Enhancing the quality of argumentation in school science. Journal of Research in Science Teaching, 41(10), 994-1020.

Reiner, M. (1998). Thought experiments and collaborative learning in physics. International Journal of Science Education, 20(9), 1043-1058.

Reis, S. M., Baum, S. M., \& Burke, E. (2014). An operational definition of twice-exceptional learners: Implications and applications. Gifted Child Quarterly, 58(3), 217-230.

Rescher, N. (1991). Thought experimentation in Pre-Socratic philosophy. T. Horowitz \& G. J. Massey (Eds.), Thought experiments in science and philosophy, (pp. 31-41). Rowman \& Littlefield.

Rogers, K. B. (2007). Lessons learned about educating the gifted and talented: A synthesis of the research on educational practice. Gifted Child Quarterly, 51(4), 382-396.

Sak, U. (2017). Üstün zekâlılar: Özellikleri, tanılanmaları, eğitimleri [The gifted: Characteristics, diagnosis, education].

Stott, A., \& Hobden, P. A. (2016). Effective learning: A case study of learning strategies used by a high achiever in learning science. Gifted Child Quarterly, 60(1), 63-74.

Toulmin, S. E. (2003). The uses of argument. Cambridge university press.

Tozlu, İ., Gülseven, E., \& Tüysüz, M. (2019). FeTeMM eğitimine yönelik etkinlik uygulaması: Kuvvet ve enerji örneği. YYÜ Eğitim Fakültesi Dergisi, 16(1), 869-896.

Villiars, C. N. (1986). Teh paradox of Schrödinger's cat. Phys. Educ., 21, 232-237.

Williams-King, E. (2005). Addressing the social and emotional needs of twice-exceptional students. Teaching Exceptional Children, 38(1), 1620.

Winebrenner, S. (2003). Teaching strategies for twice-exceptional students. Intervention in School and Clinic, 38(3), 131-137.

Yılmaz-Yenioğlu, B., \& Melekoğlu, M. A. (2020). Öğrenme güçlüğü ve özel yeteneği olan iki kere farklı bireylere yönelik yapılan çalışmaların gözden geçirilmesi. Ankara Üniversitesi Eğitim Bilimleri Fakültesi Özel Eğitim Dergisi, Erken Görünüm, 1-26. 